\title{
Probabilidades de admissão e desligamento no mercado de trabalho brasileiro
}

\author{
Douglas Uemura Nunes \\ Mestre em Economia - Insper Instituto de Ensino e Pesquisa \\ Endereço: Rua Quatá, no 300 - Vila Olímpia - São Paulo/SP \\ CEP: 04546-042 -E-mail: douglas.uemura@gmail.com
}

\section{Naercio Aquino Menezes-Filho}

Professor - Insper Instituto de Ensino e Pesquisa e FEAJUSP Endereço: Rua Quatá, n 300 - Vila Olímpia - São Paulo/SP CEP: 04546-042 - E-mail: naercioamf@insper.edu.br

\section{Bruno Kawaoka Komatsu}

Pesquisador - Insper Instituto de Ensino e Pesquisa Endereço: Rua Quatá, no 300 - Vila Olímpia - São Paulo/SP CEP: 04546-042 - E-mail: brunokk@uol.com.br

Recebido em 14/01/2015. Aceito em 02/06/2015.

\section{Resumo}

Este artigo avalia as probabilidades de admissão e desligamento no mercado de trabalho brasileiro, e mensura sua contribuição para a variabilidade cíclica da taxa de desemprego no país. Para isso, é utilizada uma metodologia recente, que permite a obtenção das probabilidades através dos estoques de empregados e desempregos, corrigindo o viés de agregação de tempo. Verificamos que, para o período de 1983 a 2001 , as oscilações da taxa de admissão foram responsáveis por $75 \%$ da variabilidade da taxa de desemprego nas principais regiões metropolitanas do Brasil. Entre 2004 e 2013 a taxa de admissão explica 80\% dessas variações.

\section{Palavras-Chave}

Desemprego. Ciclos econômicos.

\begin{abstract}
This paper evaluates the probabilities of admission and dismissal in the Brazilian labor market, and measures its contribution to the variability of the unemployment rate in the country. It uses a new methodology, which allows obtaining the probabilities through stocks of employed and unemployed correcting the time aggregation bias. We found that for the period of 1983 to 2001, the oscillations of the rate of admission were responsible for $75 \%$ of the variability in the unemployment rate in major metropolitan areas of Brazil. Between 2004 and 2013 that rate explains $80 \%$ of those variations.
\end{abstract}

\section{Keywords}

Unemployment. Economic cycles.

\section{JEL Classification}

E24. J63. J64. 


\section{Introdução}

O objetivo deste artigo é mensurar as probabilidades de admissão e desligamento no mercado de trabalho brasileiro ao longo do tempo, e avaliar a contribuição de cada uma delas para a variabilidade cíclica da taxa de desemprego no país. Visto de outra forma, buscamos analisar se, em períodos recessivos, o aumento da taxa de desemprego se deve mais ao aumento das demissões ou à redução do ritmo de contratações.

O entendimento da composição da taxa de desemprego é importante porque mudanças das probabilidades de admissão e desligamento têm implicações diferentes entre si. Em primeiro lugar, a probabilidade de admissão possui efeitos diretos sobre o bem-estar dos indivíduos, que depende mais da duração do desemprego do que do fato dos últimos estarem empregado ou não (Picchetti; Menezes-Filho, 2000). Ao mesmo tempo, é possível argumentar que uma probabilidade muito elevada de desligamento também pode ter efeito adverso sobre o bem-estar dos empregados, pela sensação de insegurança associada. Em segundo lugar, como apontam Picchetti e Menezes Filho (2000), no contexto das políticas públicas é importante diferenciar as causas das variações da taxa de desemprego. Se em períodos recessivos o desemprego cresce por um aumento das demissões, políticas que incentivassem a manutenção dos empregos existentes seriam mais efetivas. No entanto, se o contrário for verdadeiro - ou seja, se o aumento do desemprego se devesse mais à redução das admissões - uma política de incentivo a novas contratações poderia fazer mais sentido (ou, visto por outro ângulo, uma política de manutenção de empregos não seria tão relevante). Além disso, a elevação da duração do desemprego pode indicar o surgimento de grupos específicos com baixa probabilidade de admissão.

O principal objetivo deste estudo é, portanto, a análise do comportamento da taxa de desemprego com foco nas transições entre emprego e desemprego ao longo dos ciclos econômicos. Procuramos examinar qual foi o principal determinante para o comportamento cíclico da taxa de desemprego no mercado de trabalho brasileiro nas últimas três décadas, utilizando metodologias recentes para o tratamento das transições entre estados do mercado de trabalho. Utilizaremos a metodologia proposta por Shimer (2007), que permite a recuperação das duas taxas de transição de interesse (do emprego para o 
desemprego, e vice-versa) sem que se incorra no viés de agregação temporal, a partir de três séries simples: o estoque de empregados, o de desempregados, e o de desemprego de curto prazo. Uma vez obtidas, procuraremos avaliar a contribuição relativa daquelas duas séries sobre a taxa de desemprego observada. Além disso, fazemos verificações explícitas das hipóteses do modelo.

Outro ponto a ser avaliado é a validade da "hipótese da heterogeneidade" no mercado de trabalho brasileiro: em períodos recessivos, a duração do desemprego pode se elevar, porque há aumento da proporção de indivíduos com baixa probabilidade de admissão. De acordo com os cálculos realizados, verificamos que as flutuações da probabilidade de admissão responderam por cerca de $75 \%$ das variações cíclicas do desemprego no Brasil metropolitano entre 1983 e 2001, e de cerca de $80 \%$ das variações do desemprego entre 2004 e 2013. Ou seja, a importância das contratações prepondera nos movimentos do desemprego, embora as variações dos desligamentos não sejam desprezíveis. Verificamos também que alterações da composição do estoque de desempregados (avaliados grupos por sexo, idade e grau de instrução) não afetam de modo significativo a probabilidade média de admissão, sinalizando que a "hipótese da heterogeneidade" é pouco relevante para o caso brasileiro.

Na próxima seção apresentaremos uma revisão da literatura internacional e nacional relativas a avaliações de fluxos de indivíduos entre estados no mercado de trabalho, as diferentes metodologias e bases de dados aplicadas com este objetivo, e suas principais conclusões. Em seguida, na seção 3, apresentaremos a metodologia proposta por Shimer (2007) para a obtenção das taxas de transição entre emprego e desemprego, que será utilizada neste artigo. Apresentaremos ainda, naquela mesma seção, a relação entre probabilidade de admissão e duração do desemprego, o método para o cálculo da contribuição das taxas de transição para a variabilidade do desemprego, e o método para avaliação da "hipótese de heterogeneidade". A seção 4 traz maiores detalhes sobre a base de dados da Pesquisa Mensal de Emprego (PME), suas vantagens e desvantagens em relação a outras possíveis fontes de informação do mercado de trabalho brasileiro. $\mathrm{Na}$ seção 5 apresentaremos os principais resultados obtidos, e a seção 6 conclui. 


\section{Revisão de literatura}

O debate sobre as contribuições das admissões e desligamentos para os movimentos cíclicos da taxa de desemprego é bem consolidado na literatura empírica internacional e já se estende há quase vinte anos. Diferentes arcabouços teóricos, métodos empíricos e bases de dados foram empregados para a avaliação do comportamento daquelas taxas e de suas contribuições relativas, e na maior parte dos casos, a aplicação foi feita para a economia dos Estados Unidos. Entretanto, a avaliação sobre qual seria a principal fonte das flutuações da taxa de desemprego norte-americana - se admissões ou os desligamentos - não é consensual.

Por muitos anos prevaleceu a ideia de que os desligamentos eram a principal fonte das flutuações da taxa de desemprego (Shimer, 2007; Hall, 2005). Um dos primeiros estudos nesta área, e que dava suporte a esta opinião, foi elaborado por Darby, Haltiwanger e Plant (1986). A partir da suposição de racionalidade dos indivíduos que buscam emprego, estes autores argumentam que a probabilidade de encontrar emprego seria determinada, essencialmente, por características pessoais do desempregado (tais como idade, sexo, educação, etc.) e que, portanto, as admissões deveriam ser pouco afetadas pelo ciclo econômico. ${ }^{l}$ Em contrapartida, os desligamentos seriam a principal fonte de variabilidade cíclica da taxa de emprego, porque recessões são os períodos em que as demissões ocorrem em larga escala, elevando o número de desocupados na economia, e reduzindo a probabilidade geral de se encontrar um novo emprego (mesmo que o número de contratações permanecesse constante, as saídas do desemprego como proporção do estoque total de desempregados cairiam). Além disso, porque os demitidos seriam, em geral, pessoas com baixas probabilidades individuais de encontrar emprego, de modo que a composição do desemprego seria afetada negativamente pela distribuição dos desligamentos. Esta segunda justificativa é referida como "hipótese da heterogeneidade" e será discutida em detalhes mais adiante.

1 As probabilidades de admissão de cada grupo definido pelas características pessoais seriam relativamente constantes ao longo do tempo, com ajustes da variação cíclica da economia ocorrendo sobre os respectivos salários de reserva. 
Para testar sua teoria, Darby, Haltiwanger e Plant (1986) utilizam dados mensais da Current Population Survey (CPS), referentes à economia dos Estados Unidos, de 1976 a 1985. Através de decomposições, os autores avaliam a importância das probabilidades de admissão e desligamento sobre a variabilidade da taxa de desemprego observada e concluem que o nível e a composição da entrada no desemprego são mais importantes que a saída para o comportamento cíclico do mercado de trabalho, o que explicitam no título de seu artigo: "The Ins and Outs of Unemployment: The Ins Win".

Davis, Haltiwanger e Schuh (1996) também contribuíram para a visão de que as demissões são a principal fonte de flutuação do desemprego. Os autores utilizam dados de empresas industriais norte-americanas (provenientes da Longitudinal Research Datafile, de 1972 a 1993) para mensurar a criação, destruição e realocação de empregos no setor. Os autores concluem que as taxas de destruição de emprego exibem maior variação cíclica que as taxas de criação de emprego, e que, em particular, as recessões são caracterizadas por um rápido aumento da destruição do emprego acompanhado de uma relativamente leve desaceleração da criação de emprego. Para o presente trabalho, no entanto, é importante notar que a destruição de emprego pode ocorrer tanto através de demissões (o que ocasionaria um aumento da probabilidade de desligamento) ou, simplesmente, pelo não preenchimento de postos que ficaram vagos (resultando em uma redução da probabilidade de admissão) - tornando o uso dessa medida menos atraente para o objetivo proposto neste artigo. Além disso, Foote (1998) apresenta evidências de que a destruição de empregos só é mais volátil no setor industrial norte-americano.

Um terceiro artigo que dá amparo à avaliação de que as flutuações das demissões preponderam é o de Blanchard e Diamond (1990). Com dados da CPS, de janeiro de 1968 a maio de 1986, os autores fazem uso de um modelo VAR para demonstrar que, após a ocorrência de um choque negativo, o nível de emprego recua mais pelo aumento das transições do estado de emprego para o desemprego, do que pela redução das transições em sentido inverso.

Mais recentemente, utilizando novos dados e metodologias, outros autores chegaram a uma conclusão diametralmente oposta à apresentada pelos trabalhos acima discutidos. Hall (2005) utiliza dados de uma nova pesquisa (disponível a partir de dezembro de 2000), 
desenhada com o objetivo de medir diretamente os fluxos de trabalho na economia dos Estados Unidos - a "Job Openings and Labor Turnover Survey" (JOLTS). Além disso, a partir de 1994, a pesquisa domiciliar CPS passou a incluir uma nova questão para pessoas que estavam empregadas em meses consecutivos: se estas haviam mudado de emprego ou permanecido no mesmo. Esta nova informação impede que as admissões sejam subestimadas. A partir desses novos dados, e utilizando métodos econométricos, Hall estima as taxas de desligamentos e admissões desde 1948 até 2004. Suas estimativas apontam para um comportamento relativamente estável das demissões ao longo do tempo. As contratações, por outro lado, exibem comportamento bastante volátil, e seriam a principal fonte de oscilação no mercado de trabalho.

Com o desenvolvimento de uma nova metodologia para a recuperação das probabilidades de admissão e desligamento, Shimer (2007) fez uma contribuição fundamental ao debate, levando os principais trabalhos posteriores sobre o tema a adotarem essa nova forma de medida ou derivações suas (a mesma metodologia é utilizada neste artigo, e será mostrada em detalhe na seção 3.2). A principal vantagem dessa medida é de que ela trata de forma explícita o problema do viés agregação de tempo, que poderia levar a conclusões equivocadas sobre o comportamento anticíclico da probabilidade de desligamento. ${ }^{2}$ Uma segunda vantagem seria o uso de séries de dados públicas, que permitem uma fácil atualização e replicação do seu estudo.

A partir das medidas obtidas com o uso de tal metodologia e dados da CPS entre 1948 e 2007, o autor realiza uma decomposição da taxa de desemprego em termos relacionados às taxas de admissão e de desligamento, e conclui que cerca de três quartos da variação cíclica da taxa de desemprego nos Estados Unidos pode ser atribuída à variação da taxa de contratação. A taxa de desligamento, por sua vez, teria comportamento praticamente acíclico.

Fujita e Ramey (2008) utilizam as mesmas séries calculadas por Shimer (2007) e propõem dois métodos alternativos de decomposição da variância da taxa de desemprego, com ajustes de tendência por primeiras diferenças e pelo uso do filtro HP, que os leva a conclusões um pouco diferenciadas daquele autor. Para o período

2 Maiores detalhes na seção 3.2.

Estud. Econ., São Paulo, vol. 46, n.2, p. 311-341, abr.jun. 2016 
de 1976 a 2004, as taxas de admissão e desligamentos explicariam proporções comparáveis (entre $40 \%$ e $50 \%$ ) da variação cíclica da taxa de desemprego. Para os dados a partir de 1985, no entanto, a participação da taxa de desligamentos diminuiria, ainda mantendo um valor expressivo (entre 34\% e 46\%). Além disso, os autores apresentam evidências de comportamento altamente anticíclico da taxa de desligamento, com relação a indicadores do ciclo econômico (a produtividade do trabalho e a taxa de desemprego efetiva).

Elsby, Michael e Solon (2007) propõem ainda um terceiro método de avaliação das séries calculadas por Shimer (2007), e chegam a conclusões semelhantes àquelas de Fujita e Ramey (2008): a contribuição da probabilidade de contratação seria de aproximadamente $65 \%$, de modo que a taxa de desligamento explica uma parte minoritária, porém expressiva, da variação da taxa de desemprego. A principal contribuição do estudo, no entanto, é a demonstração de que os fluxos para o desemprego variam conforme o tipo de desligamento: por demissão é anticíclico, enquanto por desligamento voluntário é pró-cíclico, e por entrada na força de trabalho é acíclico.

Petrongolo e Pissarides (2008) e Elsby, Hobijn e Sahin (2008) aplicam metodologias de decomposição da taxa de desemprego a diversos países, buscando associar as diferenças de estimativas encontradas aos arranjos regulatórios de cada país. Nesse sentido, Petrongolo e Pissarides mostram que os desligamentos ganharam importância para a variação da desocupação no Reino Unido a partir de meados da década de 1980, e atribuem esta mudança a reformas na legislação do mercado de trabalho. Na França, onde a legislação de proteção do trabalho é bem mais rígida, as variações da taxa de desemprego se devem quase que inteiramente às flutuações da probabilidade de admissão. Elsby, Hobijn e Sahin (2008) expandem esse estudo para diversos países da OCDE, observando que nos países Anglo-Saxões as admissões respondem por aproximadamente $80 \%$ da variabilidade do desemprego, e que na maioria dos países europeus sua contribuição é em geral próxima a 50\%.

O número de artigos que se dedicam à avaliação dos fluxos no mercado de trabalho brasileiro é relativamente limitado. Há três trabalhos que abordam mais diretamente as questões de que estamos tratando. 
Corseuil et al. (2002) realizaram uma análise detalhada da flexibilidade do mercado de trabalho no Brasil, com foco na capacidade das empresas de criação e destruição de postos de trabalho e na rotatividade agregada. Eles utilizam dados do Cadastro Central de Empresas (CEMPRE), de 1996 a 1998 e as medidas estabelecidas por Davis, Haltinger e Schuh (1996). Os principais resultados mostram que a realocação do emprego é alta no Brasil (no mínimo 25\% entre 1997 e 1998), podendo ser dividida em partes iguais de expansão e retração de empregos, com muita heterogeneidade entre setores, regiões, tamanho da empresa.

Corseuil e Servo (2006) estenderam a análise do estudo anterior para os anos 1990. No que toca à questão que estamos examinando no presente trabalho, os autores estimam os efeitos das variáveis de criação de empregos, destruição de empregos e de rotatividade sobre a variação líquida do emprego. A estimação por efeitos fixos foi realizada com base na variação setorial (25 setores) para os anos 1991 a 2000 e seus resultados mostram que a criação de empregos apresenta comportamento cíclico, enquanto a destruição de empregos é anticíclica, com importâncias relativas semelhantes entre si. O exercício mostra ainda que a destruição do emprego em empresas que se mantiveram no mercado foi a variável com maior importância relativa para a dinâmica do emprego.

Como mencionamos anteriormente, devido ao uso dos conceitos de criação e destruição de empregos, o foco dos dois estudos mencionados difere daquele do presente estudo. A análise de Corseuil et al. (1996), além disso, concentra-se sobre as características observáveis das empresas que determinam a rotatividade, e não nos efeitos cíclicos das probabilidades de emprego ou de desemprego.

Da mesma forma que realizaremos no presente artigo, Santos (2009) utiliza a metodologia de Shimer (2007) para recuperar as taxas de admissão e desligamento e a decomposição proposta por Petrongolo e Pissarides (2008) para avaliar a importância relativa de cada uma delas sobre o comportamento cíclico da taxa de desemprego. São utilizados dados da PME entre 2002 e 2009 e, somente para a Região Metropolitana de São Paulo, da Pesquisa de Emprego e Desemprego (PED) da Fundação Sistema Estadual de Análise de Dados (SEADE), entre 1994 e 2008. Com a primeira base de dados, o autor estima que $85 \%$ da variância cíclica da taxa de desempre- 
go são explicados pela taxa de saída do desemprego, enquanto que somente $9 \%$ são explicados pela taxa de entrada no desemprego. A estimativa com dados da PED para a participação da taxa de saída do desemprego é menor (68\% para o período 1994 a 2008), porém indica o mesmo resultado qualitativo. Além disso, com um modelo VAR sobre dados do Cadastro Geral de Empregados e Desempregados (CAGED), o estudo traz evidências de que no setor formal do mercado de trabalho as admissões e demissões por iniciativa própria (quits) apresentam comportamento pró-cíclico, enquanto desligamentos apresentam comportamento anticíclico.

O presente artigo pretende contribuir para o entendimento da dinâmica do mercado de trabalho das principais Regiões Metropolitanas Brasileiras para um período mais extenso, de 1983 a 2001 e de 2002 a 2013, com um trabalho mais detalhado de verificação das hipóteses do modelo. A extensão do período de análise para os anos mais recentes nos permite abordar a questão do por que a taxa de desemprego se manteve baixa, apesar da redução do ritmo de crescimento econômico. Calcularemos medidas de probabilidade de transição entre ocupação e desocupação robustas ao problema de viés de agregação temporal, buscando avaliar sua importância para as variações cíclicas da taxa de desemprego ao longo do tempo.

Uma questão adicional associada ao debate sobre o comportamento da taxa de desemprego é relacionada à "hipótese de heterogeneidade", colocada por Darby, Haltiwanger e Plant (1986). Segundo esses autores, o comportamento do desemprego em recessões poderia estar associado às mudanças na composição dos desocupados, particularmente com o aumento relativo de grupos com baixa probabilidade de admissão nesse estado. Em seu estudo, aqueles autores defendem que as variações da taxa de desligamento, associadas somente às mudanças na composição dos desempregados, explicam a maior parte da variação cíclica da taxa de desemprego. Shimer (2007), por outro lado, rejeita a hipótese com um teste direto em suas séries de novas medidas, considerando três dimensões de variabilidade (com a metodologia detalhada na seção 3). O que seria relevante nos períodos de recessão, em consequência, é a redução da probabilidade de admissão, para todos os desocupados. Uma contribuição adicional do nosso paper é de verificar essa hipótese, utilizando a metodologia proposta por Shimer (2007). 


\section{Metodologia}

\subsection{Conceitos básicos utilizados}

No mercado de trabalho, as pessoas em idade ativa podem estar em três diferentes estados em um período de referência, compondo três respectivos estoques: de ocupados, desocupados e inativos. As pessoas ocupadas são aquelas que trabalharam, ou que tinham trabalho, porém não o exerceram (por motivos como licença). O estado de desemprego, ou desocupação, corresponde às pessoas que não estavam ocupadas, mas estavam ativamente à procura de uma ocupação. A taxa de desemprego é definida como o percentual de desempregados sobre o estoque total de pessoas ativas (ocupados e desocupados). Os inativos, finalmente, são pessoas não ocupadas, e que, por qualquer motivo, não tomaram qualquer atitude para encontrar uma ocupação: porque não queriam, não podiam, ou desistiram de procurar após certo tempo.

\subsection{Cálculo das probabilidades de transição}

Os fluxos de trabalhadores podem ser associados às movimentações de pessoas entre os três estados mencionados, em certo período de tempo (em geral um mês, um trimestre ou um ano). O foco deste artigo é sobre essas probabilidades de transição entre estados, em especial a probabilidade de admissão (ou seja, de passagem de outro estado para o de ocupação), e a probabilidade de desligamento (que pode ocorrer por saída voluntária do trabalhador, por demissão, ou outro motivo).

O uso da probabilidade agregada de admissão permite a avaliação de quão fácil ou difícil é conseguir uma ocupação em determinado ponto no tempo, e de como essa dificuldade varia de acordo com as condições gerais da economia. A variação da probabilidade de desligamento ao longo do tempo, por sua vez, pode ser associada a variações da incidência do desemprego quando os fluxos para a inatividade são pequenos.

No presente trabalho utilizaremos a metodologia de Shimer (2007) para a recuperação dessas duas probabilidades a partir de medidas discretas de estoque disponíveis pela PME. Esse modelo de tem- 
po contínuo evita explicitamente o viés de agregação temporal, que ocorreria se fizéssemos a inferência das probabilidades através das variações de estoques totais de trabalhadores e desocupados entre dois instantes no tempo. A causa do viés é de que alguns indivíduos podem mudar de estado mais de uma vez, entre os dois instantes em que as medidas foram realizadas. Por exemplo, um trabalhador pode deixar um emprego e encontrar outro em um mesmo mês, e esta transição não seria captada na avaliação da mudança dos estoques entre um período e outro. Esse tipo de problema de medição levaria a um viés anticíclico da probabilidade de desligamento, uma vez que em períodos recessivos a taxa de admissão diminuiria. Em consequência, haveria menos chances de um trabalhador que perde o emprego de encontrar outro emprego no mesmo período e, assim, mais chances de ter o desemprego medido pela pesquisa. Por outro lado, como a probabilidade de desligamento é comparativamente pequena, o viés do lado das admissões seria também relativamente pequeno. Outra vantagem desse método é de que ele permite recuperar as taxas de forma simples, contornando o problema do atrito que seria gerado caso optássemos pela observação direta das mudanças de estados dos indivíduos em um painel, como é o caso da PME.

Na metodologia de Shimer (2007) há duas hipóteses fortes. Em primeiro lugar, o autor considera apenas os estados de ocupação e desocupação, desconsiderando a inatividade, o que permite simplificar o modelo de forma bastante significativa. Shimer (2007) mostra que esta simplificação não altera a conclusão sobre as flutuações das probabilidades de transição entre emprego e desemprego ao longo tempo, com o detalhamento do modelo para três estados e utilizando medidas diretas de dados longitudinais de sua base de dados. $\mathrm{Na}$ apresentação de resultados, mostramos que há indícios de que nossos dados atendem a essa hipótese.

A segunda suposição também simplificadora é de que todos os trabalhadores são ex-ante idênticos, de modo que, em cada instante no tempo, todos os desocupados encontram emprego com probabilidades iguais. Essa hipótese poderia ser relaxada, por exemplo, pela consideração de grupos que permanecem mais tempo no desemprego, já que suas probabilidades de transição para o emprego se reduzem com a duração do desemprego (Curi; Menezes-Filho, 2006; Picchetti; Menezes-Filho, 2000). Shimer (2007) mostra analiticamente que, na presença desse tipo de heterogeneidade entre indivíduos, a pro- 
babilidade de admissão recuperada por sua metodologia representa uma média ponderada das probabilidades de admissão individuais, com uma sub-representação de desempregados de longo prazo. Por esse motivo, a probabilidade de admissão calculada a partir da duração do desemprego (que veremos na seção 3.3) deve ser em média menor do que aquela calculada diretamente. Na seção 5.2, veremos que apesar de os níveis das probabilidades serem claramente diferenciados, as flutuações das séries calculadas pelas duas metodologias são semelhantes ao longo do tempo.

Para o cálculo das probabilidades de transição, em primeiro lugar, o modelo considera que o tempo é contínuo, porém somente observado em intervalos discretos, $t \in\{1,2, \ldots\}$, e o intervalo $[t, t+1)$ é chamado "período $t$ ". Definimos $F_{t}$ como a probabilidade de que o desempregado médio encontre ao menos um emprego no período $t$ ("job finding probability"). Esta será a primeira variável de interesse. Para obtê-la, precisamos de apenas duas séries simples: o estoque de desempregados no período $t$, representado por $U_{t}$, e o desemprego de "curto prazo", $U_{t+1}^{C P}$. Em sua contrapartida empírica, o desemprego de curto prazo é representado pelo número de pessoas desempregadas há menos de um mês no período $t+1$.

Segundo o modelo, o estoque de desempregados evolui de acordo com:

$$
U_{t+1}=U_{t+1}^{C P}+\left(1-F_{t}\right) U_{t}
$$

As séries $U_{t}$ e $U_{t+1}^{C P}$ são observadas diretamente, através dos dados. Para obter $F_{t}$, basta isolá-la em (1). De modo direto:

$$
F_{t}=1-\frac{U_{t+1}-U_{t+1}^{C P}}{U_{t}}
$$

Em seguida, o autor define a taxa de transição do desemprego para a condição de emprego no período $t$ ("job finding rate", $f_{t}$ ), assumindo um modelo exponencial:

$$
f_{t} \equiv-\ln \left(1-F_{t}\right)
$$

O próximo objetivo é calcular a taxa de desligamentos (ou "separation rate", $s_{t}$ ) e a probabilidade de desligamento ("separation proba- 
bility", $S_{t}$ ). Para tanto, Shimer (2007) define uma equação em tempo contínuo para a variação do estoque de desempregados $(d U / d t)$.

Em primeiro lugar, tomemos $L_{t}$ como a força de trabalho no período t. O fluxo para dentro do desemprego é igual à multiplicação entre o estoque de ocupados $\left(L_{t}-U_{t}\right)$ e a taxa de desligamentos $\left(s_{t}\right)$. E o fluxo para fora do desemprego é igual ao estoque de desempregados no período $t\left(U_{t}\right)$ multiplicado pela taxa de admissão $\left(f_{t}\right)$. A variação do estoque de desempregados é definida como o fluxo de empregados para o desemprego, menos o fluxo de desempregados para a condição de ocupação:

$$
\frac{d U}{d t}=s_{t}\left(L_{t}-U_{t}\right)-f_{t} U_{t}
$$

Para resolver a Equação (4), o autor faz uso de um artifício algébri$\mathrm{co}$, definindo o desemprego de steady state no período $t, U^{*}$. Ora, em equilíbrio, os fluxos para dentro e para fora do desemprego se igualam, de tal forma que a variação do estoque de desocupados é nula. Ou seja,

$$
0=s_{t}\left(L_{t}-U^{*}\right)-f_{t} U^{*}
$$

Portanto, a taxa de desemprego sob a condição de equilíbrio, será igual a:

$$
\frac{U^{*}}{L_{t}}=\frac{s_{t}}{s_{t}+f_{t}}
$$

Combinando as Equações (4) e (5) e rearranjando, temos que:

$$
\frac{d U}{d t}=\left(-f_{t}-s_{t}\right)\left(U_{t}-U^{*}\right)
$$

Resolvendo a Equação (7) um mês à frente, supondo $s_{t}$, $f_{t}$ e $L_{t}$ estáveis entre $t$ e $t+1$, obtemos:

$$
U_{t+1}=U^{*}+\left(U_{t}-U^{*}\right) \exp \left(-f_{t}-s_{t}\right)
$$


Por fim, isolando $U^{*}$ em (6), e substituindo em (8):

$$
U_{t+1}=\frac{\left[1-\exp \left(-f_{t}-s_{t}\right)\right] s_{t}}{f_{t}+s_{t}} L_{t}+\exp \left(-f_{t}-s_{t}\right) U_{t}
$$

Com o valor já computado para a taxa de admissões $f_{t}$ (a partir das Equações (2) e (3)) e com os valores observados de $U_{t}$ e $U_{t+1}$ é possível recuperar o valor da taxa de desligamentos $s_{t}$ implícito na Equação (9). E, de modo análogo a (3), a probabilidade de transição para o desemprego $\left(S_{t}\right)$, é obtida através de:

$$
s_{t} \equiv-\ln \left(1-S_{t}\right)
$$

3.3. Relação entre probabilidade de admissão e duração do desemprego

A hipótese de homogeneidade ex-ante dos indivíduos pode ser violada caso haja diferenças que afetem o comportamento cíclico de suas contratações. Como sugerido na seção 2 , uma característica relevante é a diferenciação dos indivíduos relativa ao tempo de desemprego, que pode, em média, afetar negativamente as probabilidades de admissão e modificar sua dinâmica cíclica. Nesse sentido, Shimer (2007) trabalha também com uma medida alternativa de probabilidade de admissão $\left(F_{t}^{D}\right)$, baseada em sua relação com a duração média de desemprego $\left(D_{t}\right)$ :

$$
D_{t+1}=\frac{\left(D_{t}+1\right)\left(1-F_{t}^{D}\right) U_{t}+\left[U_{t+1}-\left(1-F_{t}^{D}\right) U_{t}\right]}{U_{t+1}}
$$

De acordo com a Equação (11), a duração média do desemprego em $\mathrm{t}+1$ é uma média ponderada de dois termos: $\left(D_{t}+1\right)\left(1-F_{t}^{D}\right) U_{t}$, que representa a duração dos já desempregados em $t$ que não conseguiram encontrar emprego no período, e $U_{t+1}-\left(1-F_{t}^{D}\right) U_{t}$, que representa a duração dos novos desempregados, de um mês. A partir desta avaliação, é possível calcular uma segunda medida de probabilidade de transição para a condição de ocupação:

$$
F_{t}^{D}=1-\frac{\left(D_{t+1}-1\right) U_{t+1}}{D_{t} U_{t}}
$$


Na seção 5.2 examinaremos o comportamento cíclico dessa probabilidade, com o objetivo de verificar se a heterogeneidade introduzida pela diferenciação por tempo de desemprego afetaria os resultados obtidos sob a hipótese de homogeneidade.

\subsection{Cálculo das contribuições das probabilidades de transição}

Uma vez calculadas as séries de probabilidade de transição entre ocupação e desocupação, é necessário avaliar a contribuição de cada componente para a variabilidade da taxa de desemprego ao longo do tempo. A decomposição apresentada a seguir é sugerida por Petrongolo e Pissarides (2008), que, por sua vez, baseia-se na proposta desenvolvida por Fujita e Ramey (2008). Os autores utilizam a taxa de desemprego de equilíbrio como uma aproximação da taxa efetiva de desemprego:

$$
\frac{U_{t}}{L_{t}} \approx \frac{U_{t}{ }^{*}}{L_{t}}=\frac{s_{t}}{S_{t}+f_{t}} \equiv u_{t}
$$

Em seguida, a diferença da taxa de desemprego pode ser decomposta de forma direta como:

$$
\Delta u_{t}=\left(1-u_{t}\right) u_{t-1} \frac{\Delta s_{t}}{s_{t-1}}-u_{t}\left(1-u_{t-1}\right) \frac{\Delta f_{t}}{f_{t-1}}
$$

O termo $d u_{t}^{s} \equiv\left(1-u_{t}\right) u_{t-1} \Delta s_{t} / s_{t-1}$ é definido como a porção da variação da taxa desemprego que pode ser atribuída à variação da taxa de desligamento no período $t$. De modo análogo, $d u_{t}^{f} \equiv-u_{t}\left(1-u_{t-1}\right) \Delta f_{t} / f_{t-1}$ determina o quanto a taxa de desemprego cresceu ou decresceu devido à taxa de admissão. Temos então:

$$
\Delta u_{t}=d u_{t}^{s}+d u_{t}^{f}
$$

Para avaliar a contribuição de cada componente na variância de $\Delta u$, fazemos:

$$
\begin{gathered}
\operatorname{var}(\Delta u)=\operatorname{var}\left(d u^{s}\right)+\operatorname{var}\left(d u^{f}\right)+2 \operatorname{cov}\left(d u^{s}, d u^{f}\right)= \\
\operatorname{cov}\left(\Delta u, d u^{f}\right)+\operatorname{cov}\left(\Delta u, d u^{f}\right)
\end{gathered}
$$


A contribuição de cada taxa de transição para a variabilidade da taxa de desemprego, quando considerado todo o período, é obtida através do cálculo dos "betas" de cada componente, ou seja,

$$
\beta^{s}=\frac{\operatorname{cov}\left(\Delta u, d u^{s}\right)}{\operatorname{var}(\Delta u)}, \beta^{f}=\frac{\operatorname{cov}\left(\Delta u, d u^{f}\right)}{\operatorname{var}(\Delta u)}
$$

De modo que $\beta^{s}+\beta^{f}=1$.

\subsection{Avaliação da hipótese de heterogeneidade}

Shimer (2007) propõe um método para avaliar a validade da hipótese de heterogeneidade - hipótese segundo a qual, em períodos recessivos, certos grupos de trabalhadores sofrem com demissões em massa, elevando o número de desocupados e reduzindo a probabilidade média de admissão. Em primeiro lugar, considera-se que os indivíduos possam ser classificados em $J$ diferentes grupos homogêneos, e indexados por $j$, de acordo com certas características pessoais (tais como idade e educação). Desta forma, a probabilidade média de transição de desocupação para ocupação será dada pela média ponderada das probabilidades de cada grupo,

$$
F_{t}=\frac{\sum_{j=1}^{J} U_{t, j} F_{t, j}}{\sum_{j=1}^{J} U_{t, j}}
$$

onde $U_{t, j}$ representa o número de desempregados com a característica $j$ no período $t$, e $F_{t, j}$ é sua respectiva probabilidade de admissão.

Posteriormente, são computadas as médias temporais dos estoques de desemprego e das probabilidades de admissão para cada grupo, identificadas como $\bar{U}_{j}$ e $\bar{F}_{j}$, nesta ordem. Em seguida, são calculadas duas medidas hipotéticas de probabilidade de admissão:

$$
F_{t}^{\text {real }}=\frac{\sum_{j=1}^{J} \bar{U}_{j} F_{t, j}}{\sum_{j=1}^{J} \bar{U}_{j}}, F_{t}^{\text {comp }}=\frac{\sum_{j=1}^{J} U_{t, j} \bar{F}_{j}}{\sum_{j=1}^{J} U_{t, j}}
$$


De acordo com a hipótese da heterogeneidade, grande parte das variações da taxa de desemprego estaria relacionada às alterações da composição do estoque de desocupados. Deste modo, $F_{t}^{\text {comp }}$ deveria apresentar comportamento cíclico. Por outro lado, como argumentam Darby, Haltiwanger e Plant (1986), $F_{t}^{\text {real }}$ permaneceria estável ao longo de tempo, uma vez que as probabilidades de admissão de cada grupo seriam ajustadas pelos respectivos salários de reserva. Sob as oscilações do ciclo econômico, os agentes ajustariam seus salários de reserva, de modo a reduzir a flutuação da probabilidade de admissão. Uma avaliação gráfica das duas séries permite uma comparação da contribuição de cada componente sobre a probabilidade de admissão de cada grupo.

\section{Base de dados}

A base de dados utilizada nesta avaliação é a Pesquisa Mensal de Emprego (PME), pesquisa domiciliar amostral apurada mensalmente pelo IBGE. A PME cobre aspectos conjunturais do mercado de trabalho formal e informal de seis das maiores Regiões Metropolitanas (RMs) do Brasil: São Paulo, Rio de Janeiro, Porto Alegre, Recife, Salvador e Belo Horizonte. Por conta de uma grande mudança de metodologia da pesquisa nos dados divulgados a partir de março de 2002, o grau de comparabilidade dos dados anteriores à mudança com os dados posteriores a ela é limitado. Por esse motivo, utilizamos dados de dois períodos separadamente: de janeiro de 1983 a dezembro de 2001 (antiga metodologia) e de março de 2002 a dezembro de 2013 (nova metodologia).

As mudanças da metodologia da PME incluem aspectos diversos que cobrem o desenho amostral, a abrangência geográfica e as definições empíricas de estados do mercado de trabalho e da População em Idade Ativa (PIA). Essas alterações causam mudanças nos níveis das estimativas dos estoques e das taxas de desemprego e atividade, observadas em IBGE (2002). No entanto, é tarefa complexa avaliar quais seriam os efeitos das alterações metodológicas sobre as oscilações das variáveis de interesse no presente estudo ao longo do tempo. Somente sinalizamos que a redução da idade mínima para a definição da PIA, de quinze para dez anos de idade, aumentou os níveis dos estoques em cerca de $8 \%$ em Julho de 2002 e incluiu um estrato da 
população cuja participação no mercado de trabalho é caracterizada por vínculos de trabalho de menor estabilidade. Dessa forma, esperase que as taxas e probabilidades de admissão e desligamento sejam aumentadas, porém é difícil prever qual das taxas teria oscilação mais afetada.

\section{Resultados}

\subsection{Cálculo das probabilidades de transição}

Calculamos, em primeiro lugar, a probabilidade média de se encontrar emprego ( $F_{t}$, ou "job finding probability"), conforme a Equação (2). Utilizando as Equações (9) e (10), os dados de emprego e desemprego da PME, e a taxa de admissão obtida anteriormente, calculamos a probabilidade média de desligamento em cada mês $\left(S_{t}\right.$, ou "separation probability").

As séries de emprego, desemprego e desemprego de curto prazo foram ajustadas sazonalmente, utilizando o algoritmo X12-ARIMA - mesmo método utilizado nos dados de Shimer (2007) e Petrongolo e Pissarides (2008). Além disso, para reduzir a oscilação mensal excessiva que pode ser devida a erros de medida, utilizamos médias trimestrais das estimativas mensais. Nos Gráficos 1 e 2 são exibidas as estimativas das probabilidades de transição e as taxas de desemprego, para os períodos de 1983 a 2001 e de 2002 a 2013, respectivamente. Estão destacados, nas áreas sombreadas, os períodos recessivos da economia brasileira, conforme classificação dos ciclos de negócio elaborada pelo Comitê de Datação de Ciclos Econômicos (Codace), do Instituto Brasileiro de Economia (IBRE). ${ }^{3}$

De acordo com essa datação houve seis períodos recessivos entre 1983 a 2001 e a probabilidade de admissão apresentou grandes oscilações, com tendência mais clara de decréscimo a partir de meados

3 A datação dos ciclos de negócios segue o mesmo modelo que o National Bureau of Economic Research (NBER). São considerados períodos de recessão econômica aqueles em que há "expressivo declínio no nível de atividade econômica espalhado por diversos segmentos da economia brasileira, perceptível durante ao menos dois trimestres consecutivos" (IBRE, 2009). Empiricamente, esses períodos foram determinados pelo Codace principalmente com base na série do nível do PIB trimestral dessazonalizado, porém levando em conta diversos indicadores do estado da produção, das vendas, do emprego e da renda para a confirmação dos pontos de transição. Para maiores detalhes, consultar Conjuntura Econômica (2009) e IBRE (2009). 
de 1986. A taxa de desemprego, ao contrário, teve crescimento mais nítido a partir daquele ano (a correlação simples entre as séries foi de -0,35). Nos anos cobertos pela nova série da PME (Gráfico 2, abaixo) observamos somente dois períodos recessivos, redução acentuada da taxa de desemprego e crescimento da probabilidade de admissão (com uma correlação de -0,67).

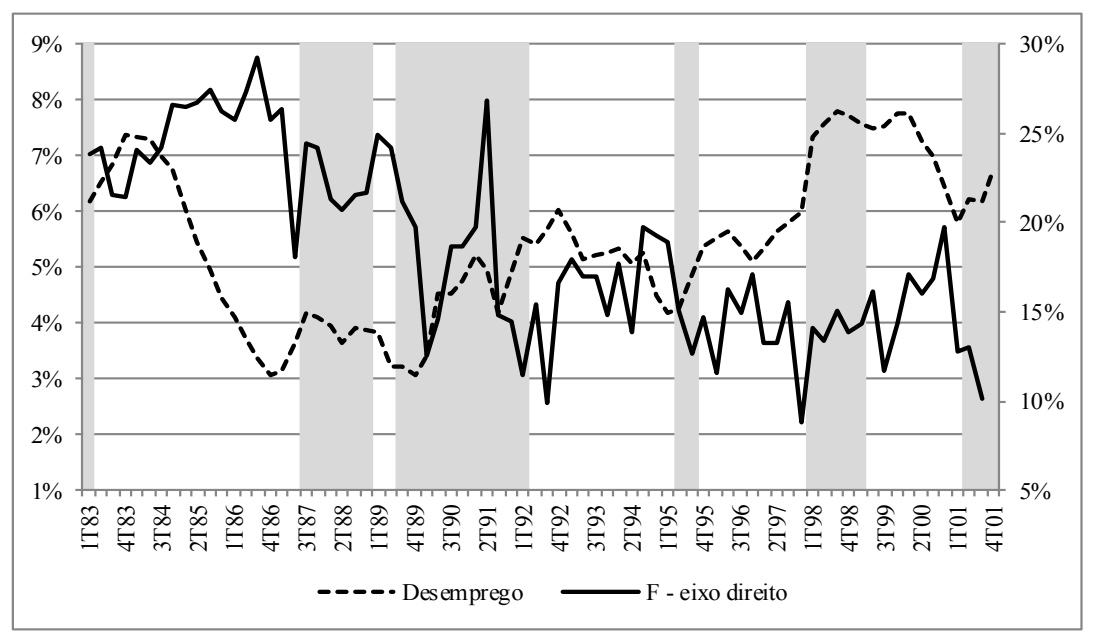

Gráfico 1 - Taxa de Desemprego e Probabilidade de Admissão (F) Fonte: PME/IBGE. Elaboração própria.

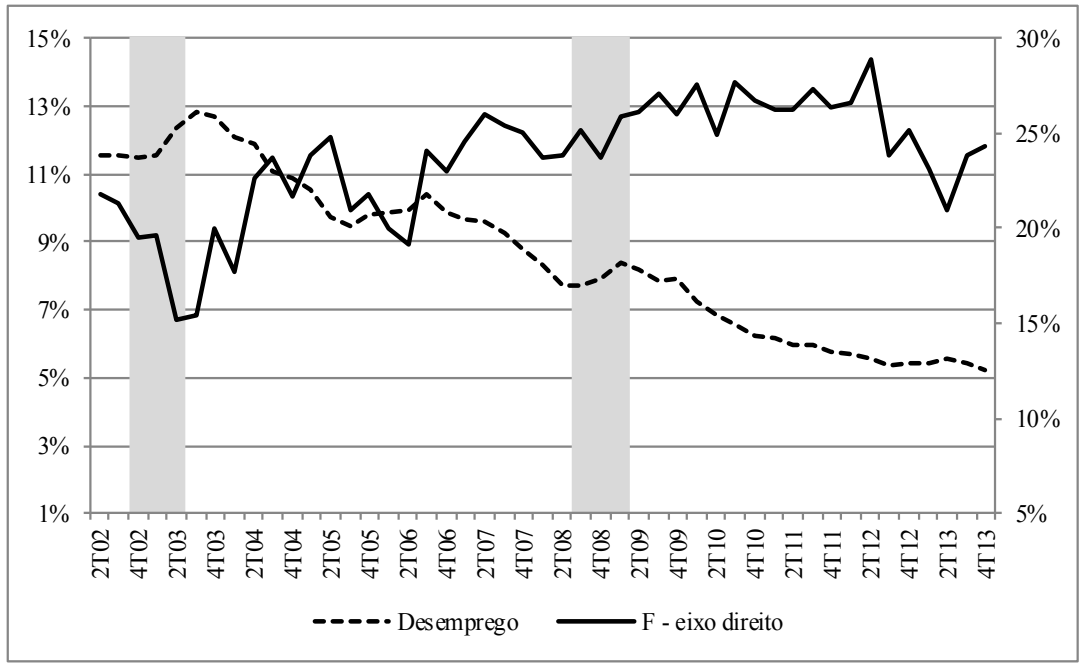

Gráfico 2 - Taxa de Desemprego e Probabilidade de Admissão (F) Fonte: PME/IBGE. Elaboração própria. 
Os Gráficos 3 e 4 exibem as probabilidades de desligamento, em comparação com a taxa de desemprego. A correlação entre as séries é de 0,57 para o período relativo à antiga metodologia da PME, e de 0,90 no período mais recente.

É importante notar que, curiosamente, a correlação entre a probabilidade de desligamento e o desemprego é negativa de 2002 a 2003. Ao que parece, a acentuada redução da probabilidade de admissão nos quatro trimestres a partir do segundo de 2002 (de 21,8\% para $15,2 \%)$ mais do que compensou o pequeno decréscimo da probabilidade de desligamento (de 3,5\% para 2,7\%) e fez com que a taxa de desemprego crescesse. Apesar do contexto de recessão econômica, a redução da taxa de desligamento pode estar relacionada ao aumento do nível de emprego no mesmo período, explicado pelo crescimento de empregos precários (IPEA, 2003). Dessa forma, é provável que naquele período tenha havido um volume significativo de transições em direção aos empregos precários, que teve efeito anticíclico sobre a taxa de desemprego. Essa explicação parece ser coerente com o nível de informalidade especialmente elevado daquele período. ${ }^{4}$

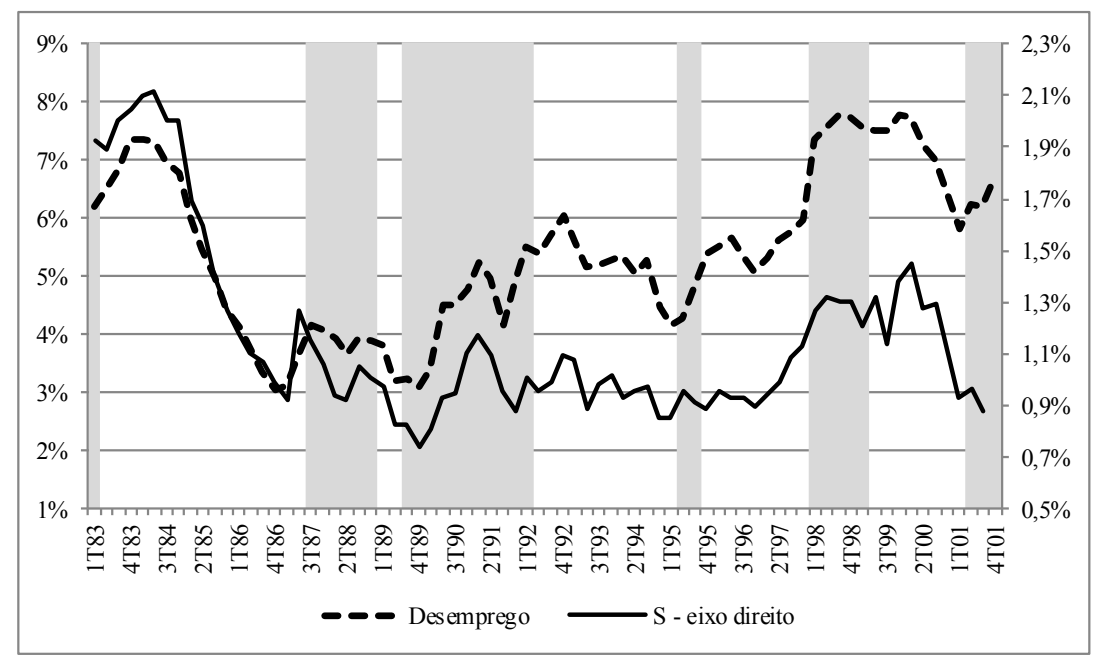

Gráfico 3 - Taxa de Desemprego e Probabilidade de Desligamento (S) Fonte: PME/IBGE. Elaboração própria.

${ }^{4}$ Uma explicação alternativa é de que nesse período recessivo os desligamentos voluntários teriam se reduzido, de modo que a probabilidade de desligamento não teria baixado significativamente. A proporção dos novos desempregados que pediu ao empregador para sair do trabalho, no entanto, aumentou de 6,5\% para 8,3\% entre o segundo trimestre de 2002 e de 2003. Essa tendência parece reforçar nosso argumento de transições para o setor informal. 


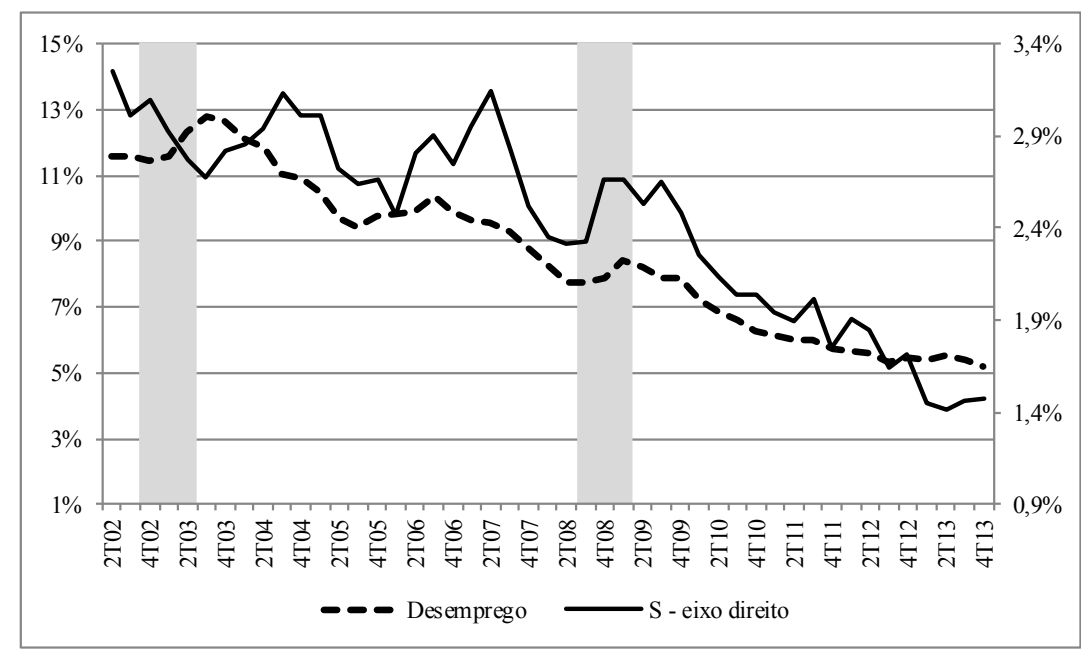

Gráfico 4 - Taxa de Desemprego e Probabilidade de Desligamento (S) Fonte: PME/IBGE. Elaboração própria

Verificamos que a probabilidade de transição para o estado de ocupação é bastante mais elevada, e suas oscilações, em termos absolutos, são mais significativas. De 1983 a 2001, a média trimestral da taxa de admissão variou entre um mínimo de 7\% e um máximo de 29\%, e seu desvio-padrão foi de 5 pontos percentuais. A probabilidade de desligamento, por sua vez, variou apenas entre $0,7 \%$ e $2,1 \%$, com desvio-padrão de 0,3 p.p. No segundo período, a probabilidade de admissão variou entre $15 \%$ e $29 \%$ (desvio-padrão de 3 p.p.), e a probabilidade de desligamento ficou entre 1,4\% e 3,3\% (desvio-padrão de 0,5 p.p.).

5.2. Relação entre probabilidade de admissão e duração do desemprego

Com o objetivo de avaliar a hipótese simplificadora de que todos os indivíduos são ex-ante idênticos, calculamos uma segunda série de probabilidades de admissão $\left(F_{t}^{D}\right)$, a partir dos dados de duração média de desemprego, conforme a Equação (12). A série de duração média também foi obtida a partir dos microdados da PME, e 
ajustada sazonalmente. No Gráfico 5 comparamos as duas medidas alternativas de probabilidade de admissão entre 2002 e 2013.

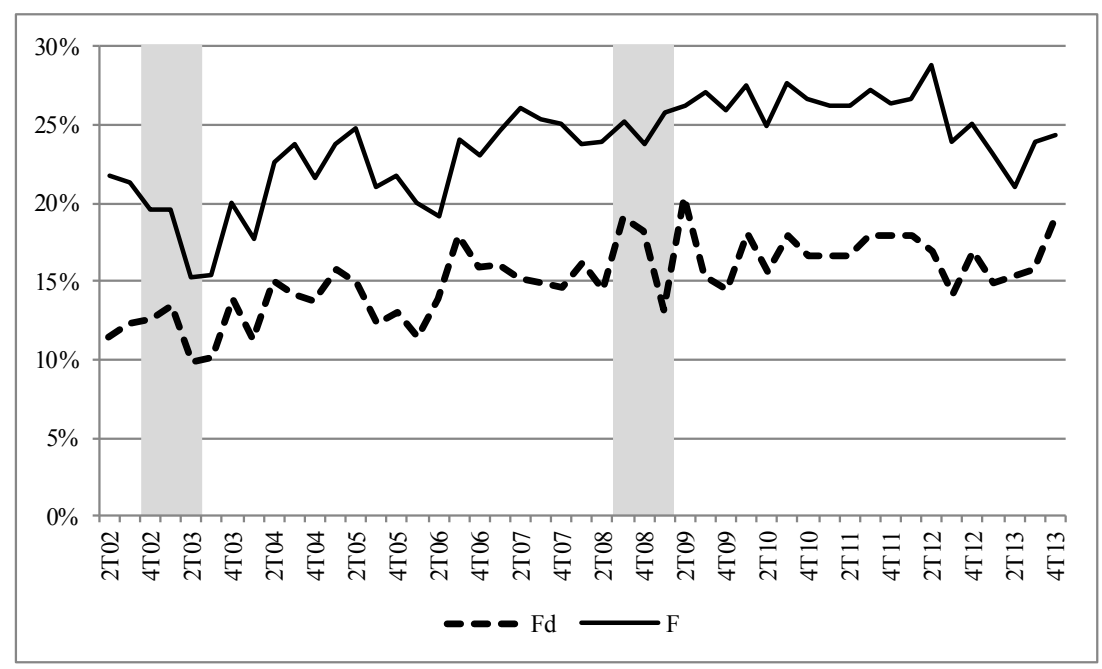

Gráfico 5 - Probabilidade de Admissão, Calculada a Partir da Duração Média do Desemprego

Fonte: PME/IBGE. Elaboração própria.

É possível observar que as séries apresentam níveis bastante diferenciados, menor para a estimativa baseada na duração, como o previsto pela derivação de Shimer (2007). Apesar disso, as flutuações das duas séries parecem ter uma relação estreita, com correlação simples de 0,77 , embora tenham sido calculadas a partir de métodos e dados primários diferentes. Dessa forma, a hipótese simplificadora de que todos os indivíduos são ex-ante idênticos não parece fazer muita diferença nos resultados.

Essa semelhança ocorre apesar do fato de que a PME deixou de incluir, com a nova metodologia, uma variável contínua para a duração do desemprego, como ocorria na antiga série. A variável categórica que a substituiu permite somente uma aproximação imperfeita da duração de desemprego em meses, um erro de medida que provavelmente impede uma maior correlação entre as séries. 


\subsection{Cálculo das contribuições das probabilidades de transição}

Uma vez calculadas as probabilidades de transição entre os estados de emprego e desemprego no mercado de trabalho, o objetivo nessa seção é avaliar as contribuições de cada uma dessas transições para a variabilidade cíclica da taxa de desemprego.

De acordo com a Equação (13), para a avaliação das contribuições utiliza-se a taxa de desemprego de equilíbrio como uma aproximação da taxa efetiva de desemprego. Shimer (2007) verifica que, para os dados dos Estados Unidos, a correlação entre a série de desemprego de equilíbrio e a série de desemprego observada um período à frente, é de 0,99. Para os dados do Brasil metropolitano, essa relação também é forte, porém bem menos estreita. Segundo as séries obtidas na seção 5.1, verificamos que a correlação entre as séries trimestrais de desemprego de equilíbrio e do valor efetivo é de 0,81 na antiga metodologia da PME, e de 0,96 para os dados de 2002 a 2013.

A diferença das estimativas entre os casos norte-americano e brasileiro provavelmente se deve à diferença de flexibilidade entre os mercados de trabalho. Nos Estados Unidos as probabilidades de admissão e de desligamento são elevadas (médias de respectivamente 45\% e 3,4\% entre 1948 e 2007 segundo Shimer (2007)), de modo que a taxa de desemprego efetiva convergiriam rapidamente para a taxa de equilíbrio (Elsby et al., 2008). O mercado de trabalho brasileiro, relativamente menos dinâmico, teria uma convergência imperfeita no intervalo de um trimestre.

O Gráfico 6 mostra que, embora ambas apresentem movimentos simultâneos de elevação e queda, a taxa de equilíbrio apresenta também alguns movimentos de curto prazo que não são verificados na taxa efetiva de desemprego. Como sugere Santos (2009), uma das razões para diferenças entre as duas taxas seria de que a hipótese do modelo que supõe transições somente entre ocupação e desemprego e força de trabalho constante não está sendo atendida. Medimos as diferenças entre as duas séries com a variação percentual média da taxa efetiva em relação à taxa de equilíbrio, medida também utilizada por Santos (2009). Na antiga série da PME o valor encontrado foi de $12 \%$ e na nova série, de $5,5 \%$. Esses valores ainda são comparáveis aos resultados encontrados por aquele autor com dados de diversos estudos internacionais (que ficam entre 4\% e 14\%); porém, 
ainda assim os desvios são relativamente grandes em alguns trechos da antiga série, de modo que os resultados devem ser interpretados com cautela.

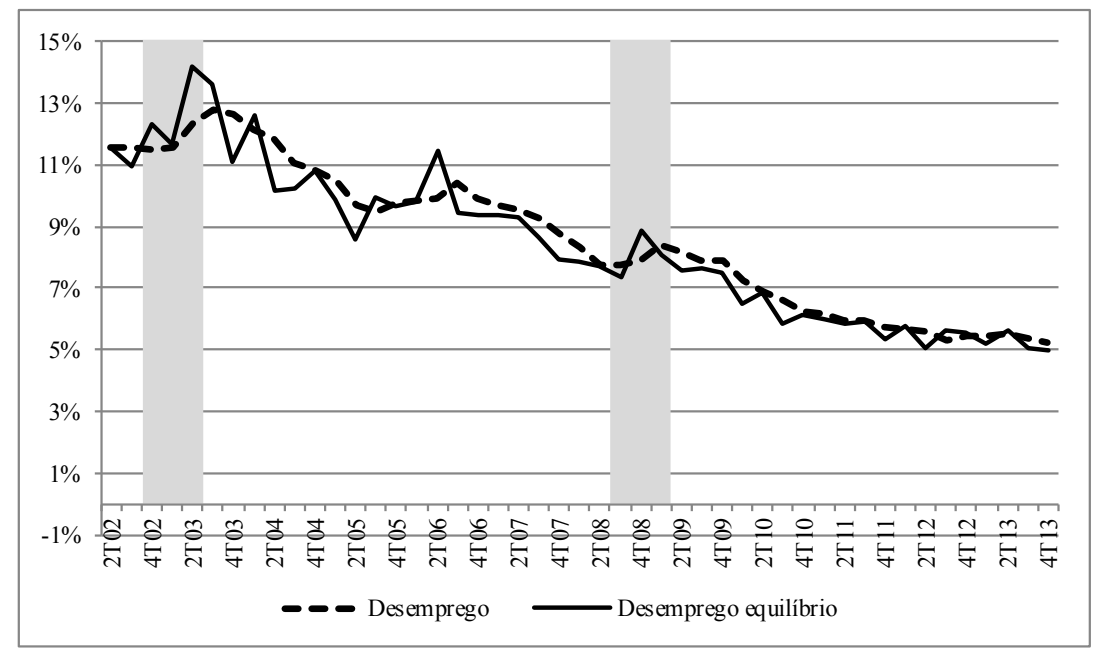

Gráfico 6 - Taxa de Desemprego de Equilíbrio e Taxa de Desemprego Efetiva Fonte: PME/IBGE. Elaboração própria.

Conforme pode ser verificado nos Gráficos 1 a 4, esses movimentos de curto prazo derivam principalmente das oscilações da probabilidade de admissão. Assim, ao utilizar a metodologia proposta por Petrongolo e Pissarides (2008) para o cálculo da contribuição de cada taxa de transição, conforme a Equação (15), obtemos que a variação da probabilidade de admissão responde por aproximadamente $93 \%$ da variância da taxa de desemprego no Brasil, e que a probabilidade de desligamento responde por 7\%, no período de 1983 a 2001. Embora a metodologia da pesquisa e a tendência da taxa de desemprego tenham se alterado no período mais recente, as contribuições encontradas são bastante semelhantes àquelas do primeiro período: de respectivamente $93,3 \%$ e $6,7 \%$.

No entanto, essas oscilações de curto prazo têm pouca relevância para a avaliação proposta neste artigo. Em primeiro lugar, porque esses movimentos de curto prazo não são verificados na taxa de desemprego efetiva. Em segundo lugar, porque as oscilações de interesse são as oscilações cíclicas, que podem ser relacionadas às variações 
de outras variáveis representativas das condições econômicas do país (tais como a produtividade).

Outros autores também encontram diferenças relevantes entre o desemprego efetivo e o valor de equilíbrio no curto prazo, em países que não os Estados Unidos. Para contornar este problema, Petrongolo e Pissarides (2008) removem da amostra pontos em que a diferença entre as duas medidas supera 10\%. Elsby, Hobijn e Sahin (2008) elaboram uma solução mais refinada, considerando esses desvios de curto prazo explicitamente em seu modelo de decomposição das contribuições das taxas de transição. Isso é realizado levando em conta que em países cujo mercado de trabalho é menos dinâmico que o norte-americano a velocidade de convergência da taxa de desemprego efetiva para a taxa de equilíbrio pode ser relativamente lenta. Santos (2009), no cálculo das contribuições das transições para o desemprego no Brasil, afirma que o ajuste proposto por aqueles autores é desnecessário em sua base de dados, uma vez que a taxa de convergência é relativamente elevada no Brasil.

No presente trabalho por simplicidade foi utilizado um filtro menos sofisticado, somente para atenuar as oscilações de curto prazo e tornar as taxas de desemprego de equilíbrio e efetiva mais comparáveis. Calculamos as médias móveis de 11 meses centradas das séries mensais e, em seguida, as médias trimestrais foram recalculadas a partir dos dados mensais filtrados. Com esse ajuste foram mantidos os principais movimentos das séries, atenuando somente as oscilações de curto prazo. Além disso, a taxa de desemprego efetiva e a taxa de equilíbrio se tornaram muito mais próximas, de modo que a correlação entre elas passou a 0,93 na antiga série e 0,99 no período mais recente.

Com a aplicação da média móvel, a amostra ficou restrita ao período do terceiro trimestre de 1983 ao segundo trimestre de 2001, e do quarto trimestre de 2002 ao segundo trimestre de 2013. Essa mudança no tratamento dos dados no geral fez com que a proporção da variação cíclica explicada pelas contratações fosse reduzida, porém se mantendo ainda como fator predominante. Repetindo a decomposição, conforme a Equação (16), verificamos que no primeiro período a probabilidade de admissão contribuiu com $74,5 \%$ da variação da taxa de desemprego no Brasil metropolitano. A probabilidade de desligamento, por sua vez, apresentou contribuição de $25,5 \%$. 
No segundo período, também utilizando as séries filtradas, verificamos que a contribuição das admissões fica em $103,5 \%$, e que o "beta" dos desligamentos é de $-3,5 \%$. Entretanto, notamos que esse resultado é afetado pelo comportamento atípico dos desligamentos entre 2002 e 2003, quando a série apresenta correlação negativa com a taxa de desemprego (ver Gráfico 4). Com efeito, se repetimos o cálculo para o período de 2004 a 2013, encontramos uma contribuição de $81 \%$ para a probabilidade de admissão e de $18 \%$ para a probabilidade de desligamento. As mesmas proporções são encontradas no cálculo para a série não alisada pelo filtro.

Uma possível explicação para uma participação menor dos desligamentos no período mais recente pode estar relacionada ao crescimento da formalização nos anos 2000. Entre 2002 e 2013, a proporção média dos ocupados que eram empregados com carteira assinada passou de cerca de $45 \%$ para 55\%, segundo dados da PME. Esse movimento poderia reduzir a importância dos desligamentos, uma vez que o custo de demissão de um empregado registrado é bem superior ao de um empregado sem carteira. Esses resultados corroboram grande parte daqueles da literatura internacional comentados na seção 2 , que mostram que a maior parte da variabilidade da taxa de desemprego de equilíbrio é explicada pelas admissões, embora os desligamentos mantenham papel relevante. Os coeficientes relativos às admissões que encontramos são comparáveis àqueles calculados por Petrongolo e Pissarides (2008) para o Reino Unido (67\%), França $(79,9 \%)$ e Espanha $(56,7 \%)$, em períodos variados. Eles também são coerentes com o percentual encontrado por Santos (2009) com a nova série da PME, somente até 2009, embora a proporção explicada pelas admissões tenha sido comparativamente menor naquele estudo $(85 \%) .{ }^{5}$ Concluímos que o efeito das flutuações das contratações para a variação da desocupação é mais relevante do que o efeito das demissões.

5 Santos (2009) também realizou a estimativa para a RM de São Paulo utilizando dados da PED entre 1994 e 2008 e chegou ao percentual de 68\%. Nossos resultados para a mesma $\mathrm{RM}$, porém no período recente foram de $80 \%$. Ao que parece, portanto, além da diferença em relação à pesquisa utilizada, aquela RM parece apresentar um comportamento da taxa de desemprego menos correlacionada com a taxa de admissão. 


\subsection{Avaliação da hipótese da heterogeneidade}

Esta seção apresenta uma avaliação da hipótese da heterogeneidade sobre a taxa de desemprego no Brasil, de acordo com a metodologia descrita na seção 3.5. O período considerado foi aquele com diversos anos de recessão entre 1983 e 2001, utilizando com as médias trimestrais dos dados mensais. Os resultados para o período mais recente não apresentam diferenças em relação às conclusões, porém não os apresentaremos por economia de espaço. Avaliamos, em primeiro lugar, a variação da participação de grupos de indivíduos com diferentes níveis de instrução, divididos em três graus de escolaridade: de 0 a 7 anos de estudo, mais de 7 a 11 anos, e acima de 11 anos de estudo. O resultado para as probabilidades de admissão é apresentado no Gráfico 7. Podemos observar que a probabilidade $F^{c o m p}$ praticamente não se altera ao longo do tempo. Em contraste, a probabilidade $F^{\text {real }}$ parece se mover conjuntamente com a probabilidade de admissão efetiva.

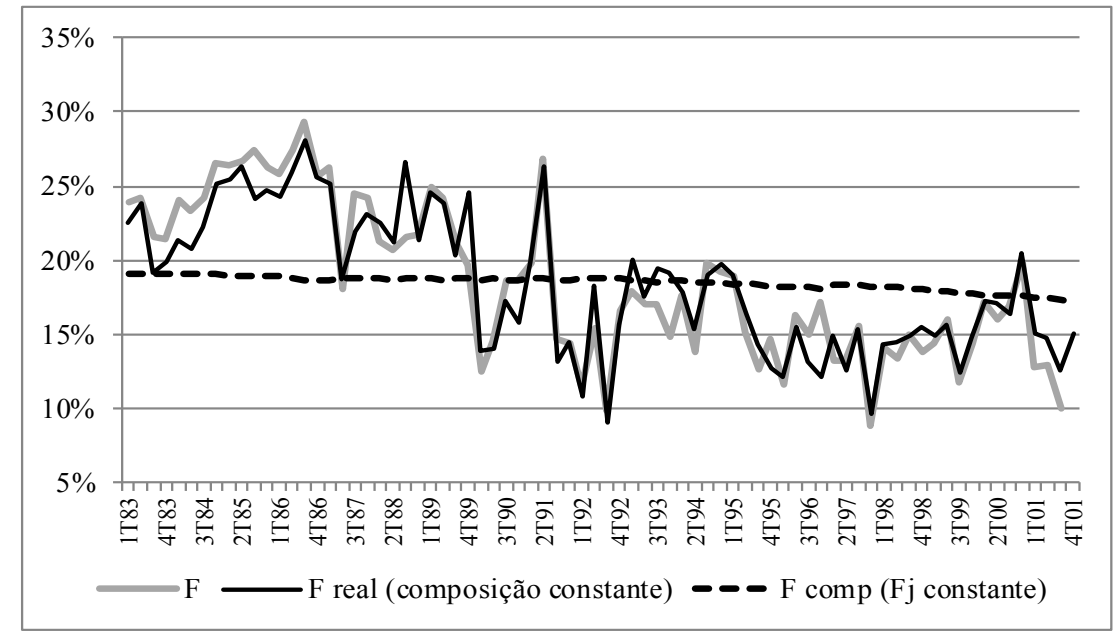

Gráfico 7 - Efeito da Composição do Estoque de Desempregados sobre a Probabilidade de Admissão - por Escolaridade

Fonte: PME/IBGE. Elaboração própria.

Em seguida, fizemos o mesmo exercício considerando as 3 faixas etárias avaliadas na seção anterior (de 15 a 24 anos, de 25 a 44 anos, e acima de 44 anos) (Gráficos 8 , abaixo). Os resultados são prati- 
camente os mesmos: a probabilidade de admissão do cenário contra factual em que a composição é constante se move juntamente com a probabilidade efetiva, enquanto a probabilidade agregada associada ao outro cenário contra factual é praticamente constante ao longo do tempo.

Tal como os resultados encontrados por Shimer (2007) para a economia norte-americana, é possível verificar que a composição do desemprego parece ter pouca influência sobre a variabilidade da probabilidade de admissão, em relação às três dimensões consideradas nessa avaliação. Ao mesmo tempo, observa-se uma alta volatilidade das taxas de admissão de cada um dos grupos de idade ou instrução. Fica claro que nos três casos a variabilidade da probabilidade de admissão agregada é explicada integralmente pelo componente que mantém constantes as participações de cada grupo no desemprego.

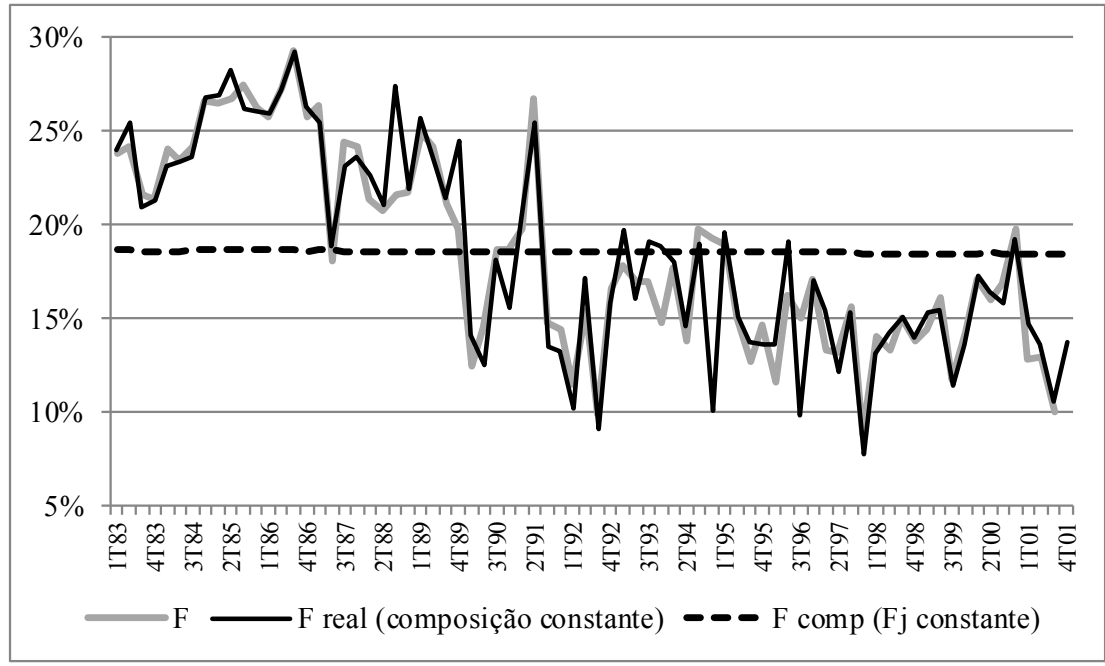

Gráfico 8 - Efeito da Composição do Estoque de Desempregados sobre a Probabilidade de Admissão - por Idade

Fonte: PME/IBGE. Elaboração própria.

Assim, concluímos que a "hipótese da heterogeneidade" tem pouca relevância para explicar as flutuações da taxa de desemprego no Brasil metropolitano. Isso significa que o comportamento pró-cíclico da taxa de desemprego é explicado pela redução da probabilidade de 
admissão entre todos os trabalhadores nas fases recessivas, enquanto que a composição do desemprego não afeta o comportamento cíclico daquela variável.

\section{Conclusões}

O objetivo deste estudo foi contribuir para preencher uma ainda ampla lacuna existente na avaliação do comportamento cíclico do mercado de trabalho brasileiro. Neste artigo, utilizamos a metodologia de Shimer (2007) para recuperação das taxas de admissão e desligamento, evitando o viés de agregação temporal. Através da decomposição proposta por Petrongolo e Pissarides (2008), mostramos que, entre 1983 e 2001, as variações da probabilidade de admissão responderam por cerca de $75 \%$ da flutuação cíclica da taxa de desemprego no Brasil metropolitano (segundo dados da Pesquisa Mensal de Emprego do IBGE). Para o período de 2004 a 2013, encontramos uma contribuição também preponderante das admissões, de cerca de $81 \%$. Estes resultados sugerem que, ao menos de forma agregada, os movimentos na taxa de desocupação se deveram mais a alterações no ritmo de contratações das empresas do que às demissões. Também verificamos que a composição do estoque de desempregados parece não ter quase nenhum efeito sobre a probabilidade média de se encontrar emprego.

Esses resultados podem contribuir para o debate sobre o efeito da regulação do mercado de trabalho sobre as probabilidades de transição. Nossas estimativas não permitem avaliar se uma regulação de proteção mais rígida do emprego aumenta ou diminui a volatilidade das demissões. Em comparação internacional, Petrongolo e Pissarides (2008) sugerem que regulações mais rígidas reduzem a volatilidade das demissões. Também é possível, no entanto, que ela altere o comportamento da probabilidade de admissão, aumentando o tempo médio de desemprego em períodos recessivos. Nossos resultados indicam somente que políticas de combate ao desemprego em períodos recessivos deveriam ter como foco esse último aspecto, das contratações das empresas. 
Por fim, verificamos que no contexto das Regiões Metropolitanas brasileiras a hipótese de heterogeneidade não é válida. Nossos resultados indicam que o comportamento do desemprego nas recessões não está associado ao desligamento em massa de grupos com probabilidade de admissão baixa e à consequente mudança de composição dos desocupados. Mostramos que o comportamento do desemprego depende da dinâmica da taxa de admissão, que responde à variação cíclica das taxas de admissão de cada grupo.

\section{Referências}

BLANCHARD, O., DIAMOND, E. The Cyclical Behavior of the Gross Flows of US Workers. Brookings Papers on Economic Activity, Economic Studies Program, The Brooking Institution, v. 21, n. 2, p. 85-155, 1990.

CAMARGO, J. M., e REIS, M. C. Desemprego: o custo da desinformação. Revista Brasileira de Economia, Rio de Janeiro, v. 59, nº 3, jul./set., 2005, p. 381-425.

CONJUNTURA ECONÔMICA. Nova Ferramenta para Acompanhar os Ciclos Econômicos Brasileiros. Conjuntura Econômica, v.63, n.06, Jun., 2009, p.30-32,

CORSEUIL, C. H., e SERVO, L. S. Criação, Destruição e Realocação de Empregos no Brasil. Brasília: IPEA, 2006.

CORSEUIL, C. H., RIBEIRO, E. P., SANTOS, D. D., e DIAS, R. Criação, Destruição, Realocação de Emprego no Brasil. Rio de Janeiro: Ipea, Texto para Discussão, n. 855, 2002.

CURI, A. Z. e MENEZES-FILHO, N. A. O Mercado de Trabalho Brasileiro é Segmentado? Alterações no Perfil da Informalidade e nos Diferenciais de Salários nas Décadas de 1980 e 1990. Estudos Econômicos, São Paulo, v. 36, n. 4, 2006.

DARBY, M., HALTIWANGER e J., PLANT, M. The Ins and Outs of Unemployment: The Ins Win. National Bureau of Economic Research Working Paper, n. 1997, 1986.

DAVIS, S. J., HALTIWANGER, J. e SCHUH, S. Job Creation and Job Destruction. Cambridge: MIT Press, 1996.

ELSBY, M., HOBIJN B. e SAHIN A. Unemployment Dynamics in the OECD. National Bureau of Economic Research Working Papers, n. 14617, 2008.

ELSBY, M. W., MICHAELS, R., e SOLON, G. The Ins and Outs of Cyclical Unemployment. National Bureau of Economic Research Working Paper, n. 12853, 2007.

FLORI, P. M. Desemprego de jovens: um estudo sobre a dinâmica do mercado de trabalho juvenil brasileiro. 2003. 77 p. Dissertação (Mestrado em Economia). Departamento de Economia, Faculdade de Economia, Administração e Contabilidade, Universidade de São Paulo, 2003.

FOOTE, C. Trend Employment Growth and the Bunching of Job Creation and Destruction, The Quarterly Journal of Economics, Oxford University Press, v. 113, n. 3, pp. 809-834, 1998.

FUJITA, S. e RAMEY, G. The Cyclicality of Separation and Job Finding Rates. Federal Reserve Bank of Philadelphia Working Paper, n. 07-19, 2008.

HALL, R. E. Job Loss, Job Finding, and Unemployment in the U.S. Economy over the Past Fifty Years. National Bureau of Economic Research Working Paper, n. 11678, 2005. 
IBGE. Notas Técnicas. Instituto Brasileiro de Geografia e Estatística, dez. 2002. Disponível em: http:// www.ibge.gov.br/home/estatistica/indicadores/trabalhoerendimento/pme nova/defaultnotas.shtm. Acesso em dezembro de 2013.

IPEA. Análise do Mercado de Trabalho. Boletim Mercado de Trabalho - Conjuntura e Análise, n. 22, nov. 2003.

MENEZES-FILHO, N. Costs of Displacement in Brazil. Universidade de São Paulo, 2004.

NERI, M., COELHO, D., ANCORA, M. e PINTO, A. Aspectos Dinâmicos do Desemprego e da Posição na Ocupação. Estudos Econômicos, v. 27, n. especial, p. 137-159, 1997.

PETRONGOLO B. e PISSARIDES, C. A., The Ins and Outs of European Unemployment, American Economic Review, v. 98, n. 2, pp. 256-262, May 2008.

PICCHETTI, P. e MENEZES-FILHO, N. Os Determinantes da Duração do Desemprego em São Paulo. Pesquisa e Planejamento Econômico, v. 30, n. 1, 2000.

RIBAS, R. P e SOARES, S. S. D. Sobre o Painel da Pesquisa Mensal de Emprego (PME) do IBGE. Texto para discussão, n. 1348, Instituto de Pesquisa Econômica Aplicada - IPEA, 2008.

SHIMER, R. Reassessing the Ins and Outs of Unemployment. National Bureau of Economic Research Working Paper, n. 13421, 2007.

SANTOS, F. The Ins and Outs of Cyclical Unemployment in Brazil: a first assessment. $31^{\circ}$ Encontro da Sociedade Brasileira de Econometria, out. 2009. Disponível em: http://bibliotecadigital.fgv. br/ocs/index.php/sbe/EBE09/paper/view/1026. 